\title{
Movement and Clay
}

\author{
By: Sherri-Lynn Yazbeck
}

Sherri-Lynn Yazbeck is an early childhood educator and supervisor of a 3- to 5-year-old program at the University of Victoria's Child Care Services. She strives to be in a state of exploration, wonder, and dialogue with the children, families, materials, and her fellow educators at the centre. She finds joy in the ordinary moments of the day and loves to find comfort in those uncomfortable moments of inquiry and question.

Our program, like many other early childhood programs, is an environment of emergent and playbased programming for twenty-five 3and 4-year-old children. In September 2011 we decided to introduce clay into our program. We had been moving toward presenting materials in our space that are open ended, rather than fixed or prescribed in meaning, and that allow for change. Materials that inspire imagination, creativity, and exploration. It was hoped that the introduction of clay would extend on and allow for a creative and divergent thinking process that only open-ended materials can provide for the children, families, and educators of the centre. What follows are my reflections on our work with clay: how this material led us to a state of inquiry, exploration, wonder, and dialogue. The story of how clay became alive in our space, our ideas, and our minds and ultimately led us to a line of flight we couldn't have imagined, a place of new questions and changing dialogues.

At the time of the introduction of clay into the centre, I was also interested in the idea of movement-movement of children, materials, and time. Many strides had been made in our work with children and the idea of movement of bodies and time in our space, but I wondered about movement of materials. Specifically, I wondered if the children were reluctant to move materials because we educators had created both visible and invisible boundaries. Vecchi (2010) writes:
We must evaluate in everyday life how much environments allow for or forbid, how much they encourage or censor, how much they educate ways of seeing, exploration or sensibility. The extent to which personal sensibilities and culture can grow on journeys of this kind is often underestimated, as are the effects it can have on our relationships with children, the surrounding environment and educational work. (p. 89)

I wondered how could we expand the children's work with the ideas of materials and movement using clay as a starting point in our environment.

My colleagues and I hoped that by letting go of some of our ideas of "space for things to happen" the children would embrace the idea and begin to explore and experience clay in relationship to themselves and other materials throughout the environment. We decided we would introduce clay by engaging in project work once a week, hoping that clay would become a staple material in our centre as the year went on. During the initial encounters, clay was put on the red table in large chunks with beach glass, bamboo sticks, and dinosaurs. We chose to first present clay as large forms because we wanted to reveal clay in the classroom in a form closest to how we received it. Honestly, we didn't know how to start or to introduce clay, and the above-mentioned items were things we had regularly seen the children engage with. Much of the time during these first sessions was spent putting things into clay, digging, and describing the physical properties of the large blocks; heavy, sticky, and hard were words often heard. Hiding, decorating, and making holes and homes were common discussion threads heard during these initial encounters. In the beginning there was also discussion on what the clay was. For some it resembled coffee play dough in both texture and smell, while others were adamant that "it is clay, it is different!"

During these initial explorations, nothing was added by the children. They did not move anything to or from the clay and clay itself was not moved from the table. After a month of presenting clay on the red table, alone and with the materials chosen by the educators, Emily went to the shelf and picked up the sea creatures. We watched in silence as she swam the creatures through the clay sea, put them into their homes, and fed them small pieces of clay and beach glass. Soon after that session, several items came to the table - knives, wiggly glue, cloth, pencils, and tree stumps joined the children and clay. The relationship between children and clay was changing, but still clay itself was not moving from the table.

We wondered why the children chose to work with clay only in the area we had placed it in. Did our environment forbid or censor movement? Had we put things into categories without realizing it? Kind (2010) suggests, "There is an incredible richness, variation, and eclecticism in what children do. In many ways educators limit this richness or provoke a narrowing of experience by what we think, what we expect, and the frames we use to interpret children's artistic explorations" (p. 116). Were we limiting the possibilities of clay with past thoughts? What frames were we using to question and make interpretations? To stimulate dialogue 
and reflection with the children, I printed some of the photos of our experiences. It was at this point that Jordan, a child looking at the photos, asked, "Why is clay always at the red table?" An educator nearby responded, "Where should clay be?" Looking around the room, Jordan quickly replied, "At the green table under the painting" [pointing to a group painting done by the children]. At the next session, clay took place at the green table, again in large forms. However, this experience was different: The children asked for water. We gave them small cups of water, but it wasn't enough; they needed more. The children poured the water over the clay, rubbed the clay and smoothed it out, and then would head to the bathroom to get more water. Water began to flow off the table. Some worked the water into the clay, while others continued to pour water over their block, watching it flow down over the sides and onto the table and eventually drip to the floor. This went on for an hour or so, with children coming and going from the area. Some concerns about safety and the amount of water on the floor were expressed, and the session ended with the children using paper and cloth towels to mop up the water. Later that day Jordan requested that clay be moved to the yellow table for the next session.

At the following session, clay was displayed in large forms on the yellow table when the centre opened. When I arrived about an hour later, I saw extremely wet mounds of clay on the table and water pouring off and flowing into a drain on the floor in the nearby bathroom. No children were working with the clay. Towels had been placed over large puddles and I was able to follow a trail to the bathroom sinks, where I found an educator trying to control the flow of water. She explained that the children had been bringing water from the bathroom to the clay and things got a bit out of hand. Clay closed early that day.

The amount of water the children used made us uncomfortable - uncomfortable with water, uncomfortable with mess, and uncomfortable with each other because we disagreed on the need for water that some of the children were expressing when working with clay. We wondered: What are our boundaries? How far could we take this? When does the need for safety override the need for exploration? Why do some children need water to explore clay while others show no interest when water is present? And what were we going to do with clay?

We decided to have clay available in the areas suggested by Jordan, the only child who had wished to move it. Clay was put into plastic airtight containers on the shelves by the red, blue, yellow, and green tables. We decided that if the children were directly supervised we would welcome water at the yellow and green tables because the water source was nearby. I did not feel good about this. I felt as if we were creating more boundaries, boundaries I was so desperately wanting to break down. The containers also felt cold and unwelcoming. We had been thinking a lot about the aesthetic characteristics of our space, and the containers did not fit the direction we were going. Those buckets sat on the shelves for almost a month and clay never came out. Each time I looked at it my body tensed, I tried to ignore them, but each time I passed by the shelves I felt uncomfortable. Eventually, I couldn't stand looking at them: Clay was not appealing to me or the children in this form. So I put the containers and clay away. Was this the end of clay for us?

Interestingly, while we saw no work or movement of clay for those few weeks, we did see movement of other materials in our space. We noticed the children using things in different ways and in different areas. Materials were moving. We wondered if deliberately deciding to relax boundaries with clay had led us to unconsciously let go of boundaries in other areas. Materials were now moving, ideas and play were changing, a creative, imaginative, and divergent thinking process was happening before our eyes. We began to wonder whether the frame through which we view children and materials was changing.
Excited by this new turn of events, I was not yet ready to give up on clay. I had seen the relationship between the children and clay beginning to change and I wanted to explore more. We had a staff meeting before winter break and decided to continue our explorations, understanding that some educators and children were not comfortable and may choose not to take part. We agreed that clay would be tried in the water table, allowing for some containment of water. Based on my observations of the children exploring materials in our space, I suggested also presenting clay in a different way. The children had been showing an interest in small stones, spools, jewels, and treasures. What if clay was presented in this way? Would movement happen? What was it about the idea of movement that I couldn't shake? Spools, jewels, and other small items could be found moving about the room, taking on new roles and responsibilities. Would small clay balls elicit the same response? A practicum student and I rolled close to 400 clay balls of varying size.

Clay was presented in the water table and as balls on the tables over the next several sessions. Some children were drawn to water and clay; others gravitated to the small balls. Balls were collected, rolled, and flattened. Pencils were used to write and draw on clay and knives to cut clay balls into pieces. Snowmen and birds were made and then flattened by large tree rounds. Children came and left. Water was poured; clay became wet, thick, and gooey. We covered our hands and arms, filled jars, and poured more water. We turned clay into paint and used brushes; we made clay balls wet and sticky. Clay became diverse, similar to the way that Munnelly (2010, p. 16, quoting Bergson, 1929, p. 196) describes the experience of drawing: "The body acts as a place of passage of the movements received and thrown back, a hyphen, a connecting link between the things that act on me and the things upon which I act"; Munnelly says that Bergson's statement "eloquently captures both the corporeal and cerebral experience of drawing where the body is 
governed by a triumvirate of movement, cognition and material" (2010, p. 16). Clay was acting on us and we on it. For the first time in my exploration with clay, I was comfortable. I was able to let go of some of my hesitations and just be in the moment. I had opened myself up to see the extraordinary in the everyday moments with clay. I was in that one place, being totally present with that one child or group of children and not trying to control, through a lack of or need for movement. The children were beginning to understand clay and to teach me, through their explorations, the "way of clay."

However, when each session would end I couldn't help but wonder, why is clay always worked with in the area where it is arranged by the educators? I felt we were letting go of our boundaries with materials in our space and we were seeing so much movement of everything else. Maybe clay didn't need to move for the children to come to understand it. I began to think about our days: What is it about clay, the children, the environment, and the educators that does not inspire clay to be moved and worked with in another space? And why couldn't I stop thinking about the need for clay to move?

During this time a fellow educator and I presented our experiences with clay in an art inquiry course we were taking with a small group of early childhood educators. As we talked about our experiences and tried to answer the group's questions, I was left wondering if, while we were working to remove material-movement boundaries, we were in fact creating boundaries for ourselves. Why were we, the educators, so reluctant to move clay ourselves? We claim to view the children as protagonists, as active constructors of their own knowledge, but aren't we too protagonists, acting as co-constructors of that knowledge and observing, facilitating, and inspiring possibilities to unfold, in both the children and the clay?

The next day I went to work early and moved clay into the block space. Initially, the children seemed hesitant, pulling blocks off the shelf but not really engaging with the clay. Eventually one child got a block, put it on a chunk of clay, stomped on it, and lifted the block to reveal a very flat piece of clay. Soon the room was buzzing with conversation and questions: How did you do that? This works better, it is heavier. How is yours so flat? Did you step on it? The dialogue and work continued for almost two hours until slowly children left to go outside. Those of us who remained cleaned up the clay, swept and vacuumed the carpet, and wiped down the blocks. Our sessions in the block space continued for several weeks, not always on the same day, sometimes initiated by the children's requests and other times by myself. As time went on more children came to work with clay and blocks, some who had never engaged with the material when it was presented on the tables. The clay became the bolts holding the ships and machines together; we discovered that it sticks to walls; we added water by way of wet paper towels; we made designs using our shoes, knives, straws, bamboo, glass beads, and pencils, all brought to the clay by the children. Dry clay became chalk and wet clay became mortar. Our understanding of clay was growing and changing once again. Our relationship with the material was strengthening.

This year with clay has allowed us to let go of visible and invisible boundaries, boundaries within ourselves and boundaries we set up for children, materials, and our space. We have questioned both our practice and the design and aesthetics of our environment, and we have opened ourselves up to be coconstructors of experience and exploration with the children. Now that we-children and educators-move clay and other materials throughout the room, clay is taking on new roles and responsibilities.

Some children are drawing plans and are deliberately sculpting cups, dogs, penguins, birds, and snakes. We are learning that dried clay needs to be fired or it is extremely fragile, and we are working to make connections with some professional potters. As educators we are discussing how the process of exploration can lead to a product through understanding and relationship forming. We wonder if a product can ever be finished or if it is always in process. We are considering Burrington's (2004) thoughts on the importance of time-

time for observing life, time for entering play, time for building relationships and time for revisiting ideas and experiences. It takes a long time to learn to use tools and to understand media. No person is born knowing how to write, how to move a paintbrush or dance or write music. No child enters the classroom asking to represent their thinking and state their questions with clay either. It takes time. And it takes teachers who honor that way of being with childrenteachers who enter the natural time frame of children. (p. 84)

Letting go and seeing the children as protagonists and researchers and allowing myself to take on similar roles has given us all an opportunity to understand clay in a different way. Clay, like the other materials in our space, is a living part of our environment; it has become a language to express feelings and thoughts, a form of expression, representation, wonder, desire, understanding; and inquiry. Clay is all of this, with or without movement, alone or with other materials, and in many forms.

\section{References}

Burrington, B. (2004). Afterword. In D. Smith \& J. Goldhaber (Eds.), Poking, pinching and pretending: Documenting toddlers' explorations with clay (pp. 8387). St. Paul, MN: Redleaf.

Kind, S. (2010). Art encounters: Movements in the visual arts and early childhood education. In V. PaciniKetchabaw (Ed.), Flows, rhythms, and intensities of early childhood education (pp. 113-131). New York, NY: Peter Lang.

Munnelly, L. (2010). Dialogues in proximity. Studies in Material Thinking, Volume 4. Retrieved from: http:// www.materialthinking.org/papers/13

Vecchi, V. (2010). Art and creativity in Reggio Emilia: Exploring the role and potential of ateliers in early childhood education. New York, NY: Routledge. 